\title{
Symmetry Break of Special Pair: Photochemically Induced Dynamic Nuclear Polarization NMR Confirms Control by Nonaromatic Substituents
}

\author{
Karthick Babu Sai Sankar Gupta, ${ }^{\dagger}$ A. Alia, ${ }^{\dagger, \S}$ Huub J.M. de Groot, ${ }^{\dagger}$ and Jörg Matysik ${ }^{*}{ }^{\dagger, \ddagger}$ \\ ${ }^{\dagger}$ Institute of Chemistry, Leiden University, P.O. Box 9502, 2300 RA Leiden, The Netherlands \\ ${ }^{\ddagger}$ Institut für Analytische Chemie, Universität Leipzig, Linnèstr. 3, 04104 Leipzig, Germany \\ ${ }^{\S}$ Institut für Medizinische Physik und Biophysik, Universität Leipzig, Härtelstraße 16-18, 04107 Leipzig, Germany
}

Supporting Information

\begin{abstract}
Despite the high structural symmetry of cofactor arrangement and protein environment, light-induced electron transfer in photosynthetic reaction centers (RCs) of the purple bacterium Rhodobacter sphaeroides runs selectively over one of the two branches of cofactors. The origin of this functional symmetry break has been debated for several decades. Recently, a crucial role of the substituents has been proposed by theoretical studies [Yamasaki, H.; Takano, Y.; Nakamura, H. J. Phys. Chem. B 2008, 112, 13923-13933]. Photo-CIDNP (photochemically induced dynamic nuclear polarization) MAS (magic angle

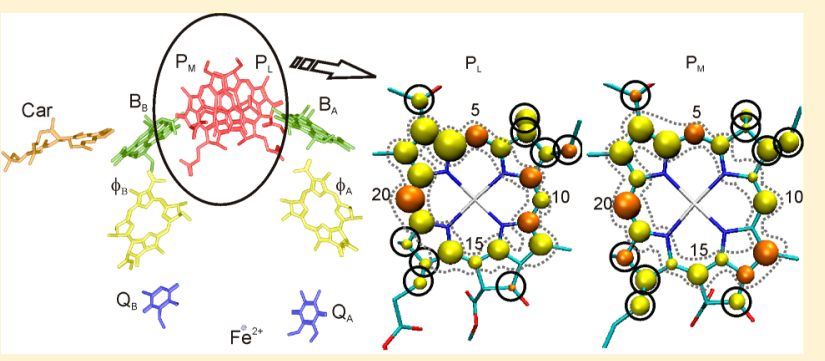
spinning) NMR demonstrates that indeed the peripheral atoms show opposite electronic effects on both sides of the special pair. While the aromatic system of $P_{L}$ receives electron density from its periphery, the electron density of the aromatic ring of $P_{M}$ is decreased.
\end{abstract}

\section{INTRODUCTION}

Photosynthetic RCs are excitonic solar energy converters, and light shining onto a photosynthetic membrane in the cell will initiate charge separation. Excitons and charge transfer states in organic assemblies have relatively high binding energies of several tenths of an electronvolt. ${ }^{1}$ In natural photosynthesis, however, charge separation is remarkably efficient and is thought to be almost barrier-less. ${ }^{2}$ The cofactors of photosynthetic reaction centers (RCs) of Rhodobacter ( $R$.) sphaeroides purple bacteria form two branches arranged in a nearly $C_{2}$ symmetry, including the special pair (P) formed by two overlapping $\mathrm{BChl} a$ (Figure 1).,4 Functional studies have shown that charge transfer occurs selectively into the so-called A-branch (for review, see refs 5 and 6). The question for the origin of the symmetry break became recently even more puzzling because RCs of photosystem I, having a similar arrangement of cofactors, transport electrons over both branches. $^{7,8}$ For the functional symmetry break in $R$. sphaeroides, the unidirectionality of charge transfer is encoded in the molecular structure of these RCs, in particular, for the special pair and its direct environment. ${ }^{9}$ Many inherent asymmetries exist involving the $\mathrm{BChl} a$ dimer, for example, (i) different shapes of the macrocycles; (ii) the overlap of the dimer is larger with $\mathrm{B}_{\mathrm{A}}$ than with $\mathrm{B}_{\mathrm{B}}$; (iii) bacteriopheophytin $\Phi_{\mathrm{A}}$ is $1.5 \AA$ closer to $\mathrm{B}_{\mathrm{A}}$ than $\Phi_{\mathrm{B}}$ is to $\mathrm{B}_{\mathrm{B}}$; (iv) binding of the cofactors to the protein is different; (v) distribution of charged amino acids is asymmetric; (vi) the side chains are not symmetrically arranged. In particular, conformational control by the acetyl groups in $\mathrm{P}_{\mathrm{L}}$ and $\mathrm{P}_{\mathrm{M}}$ was proposed. ${ }^{10}$

A recent time-resolved photo-CIDNP MAS (photochemically induced dynamic nuclear polarization magic angle spinning) NMR study on the special pair strongly suggests that internal reasons are sufficient to explain the observed symmetry break on the electron spin density distribution of the radical cation state. ${ }^{11}$ Resonance Raman spectroscopy and photo-CIDNP MAS NMR have demonstrated differences in the electron distribution of the electronic ground state of the special pair. ${ }^{1-13}$ As shown with ENDOR and photo-CIDNP MAS NMR, the electron spin density of the radical cation of the special pair is asymmetric in favor of the $P_{L}$ cofactor. ${ }^{11,14,15}$ One might therefore conclude that differences in orbital factors of overlapping static orbitals of nearby cofactors affect the kinetics of electron transfer. ${ }^{11,16}$ Furthermore, stressed by the observation of marker modes related to electron transfer, ${ }^{17-22}$ a dynamic role of local vibrational modes has been proposed to cause the symmetry break. Assignments of these low-frequency vibrational modes to local molecular structures have been proposed. ${ }^{23,24}$ To explain such differences between the two sides, a recent theoretical study ${ }^{25}$ proposed a crucial role of conformations of side chains of the BChl $a$ macrocycles of the aromatic systems. The work suggests that different side-chain conformations are able to tune the electron spin distributions

Received: March 3, 2013

Published: June 6, 2013 

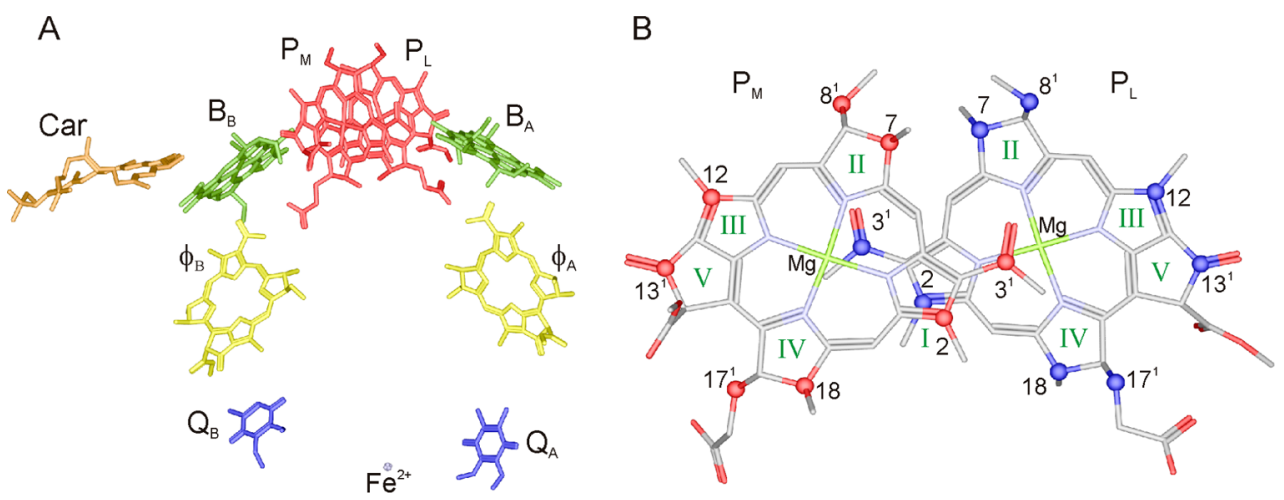

Figure 1. (A) Arrangement of cofactors in reaction centers (RCs) of wild-type (WT) Rhodobacter sphaeroides. The primary electron donor, the special pair, is formed by the two bacteriochlorophyll (BChl) a molecules $\mathrm{P}_{\mathrm{M}}$ and $\mathrm{P}_{\mathrm{L}}$. $\mathrm{B}_{\mathrm{A}}$ and $\mathrm{B}_{\mathrm{B}}$ are accessory $\mathrm{BChl}$ cofactors; $\Phi_{\mathrm{A}}$ and $\Phi_{\mathrm{B}}$ are bacteriopheophytin (BPhe) cofactors. On the acceptor side, two ubiquinone-10 cofactors $\mathrm{Q}_{A}$ and $\mathrm{Q}_{B}$ are located with a non-heme iron in between. The symmetry of the cofactor arrangement is broken by a carotenoid (Car) cofactor. The light-induced electron transfer occurs selectively via branch A. (B) Spatial arrangement of the two cofactors $P_{L}$ (right, isotope labels in blue) and $P_{M}$ (left, isotope labels in red) forming the special pair. The pyrrole rings are indicated with Roman numbers. Pyrrole rings I are overlapping. The isotope labeling pattern has been obtained by feeding with $3-{ }^{13} \mathrm{C}_{1}-\delta$-aminolevulinic acid (3-ALA; see Figure 2). The long side chains are omitted to provide a better view on the arrangement of the active elements in the charge separation process [pdb entry 1M3X; the figure has been made with Accelrys Discovery Studio, San Diego, CA].

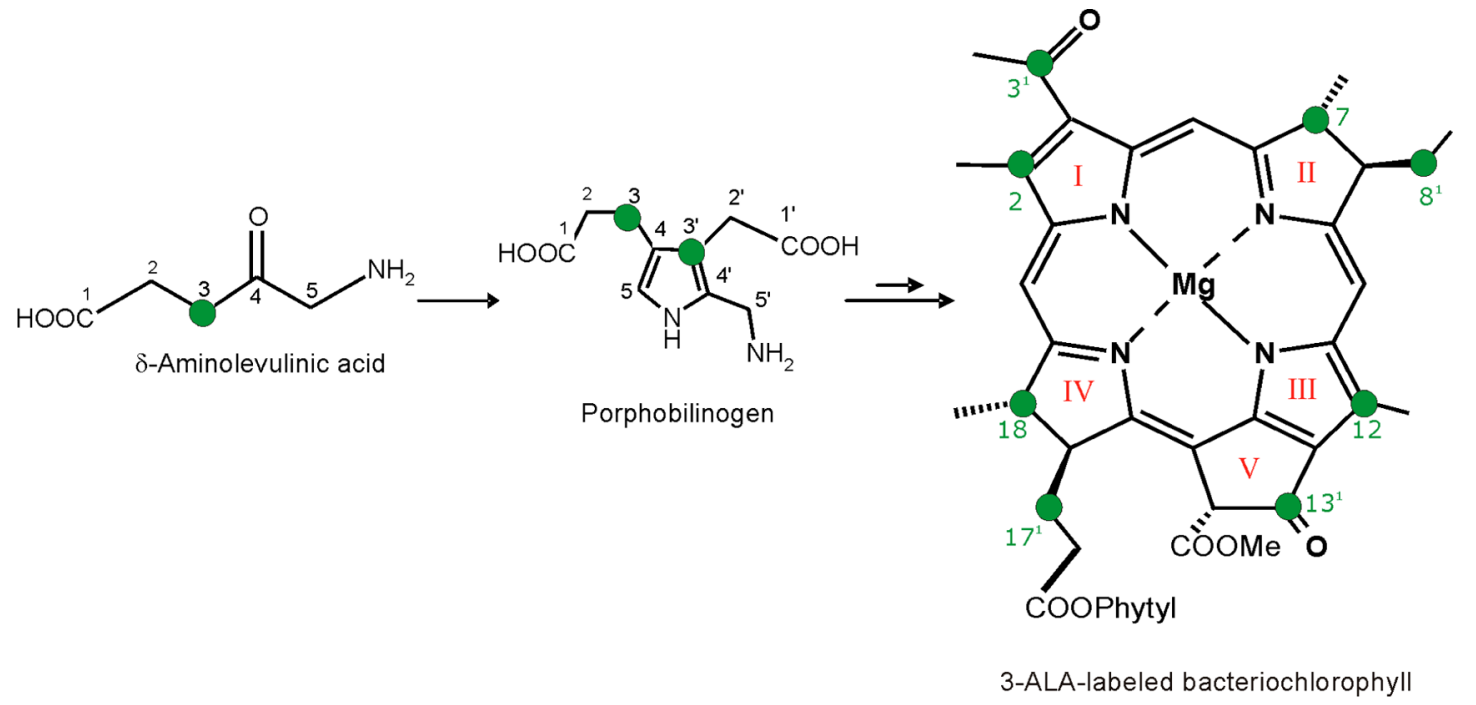

Figure 2. Biosynthetic pathway for the formation of selectively ${ }^{13} \mathrm{C}$ isotope-labeled bacteriochlorophyll (BChl) $a$ by feeding the bacteria with $3-{ }^{13} \mathrm{C}_{1}{ }^{-}$ $\delta$-aminolevulinic acid (3-ALA).

over both halves of the special pair from almost 100:0 to 0:100. In the present paper, photo-CIDNP MAS NMR is applied to test this hypothesis.

The solid-state photo-CIDNP effect (for reviews, see 26-28) discovered by Zysmilich and McDermott in 1994 in frozen and quinone-blocked RCs of $R$. sphaeroides $\mathrm{R} 26$ by ${ }^{15} \mathrm{~N}$ MAS NMR upon continuous illumination with white light offered NMR access to the electron-nuclear processes during the charge separation. By induction of a non-Boltzmann nuclear spin order upon the photoreaction, a signal enhancement of a factor of more than 80000 has been observed by ${ }^{13} \mathrm{C}$ MAS NMR for several RCs. ${ }^{15,29,30}$ In the meantime, the solid-state photoCIDNP effect has been observed for various RCs of bacteria, algae, and plants. ${ }^{31-37}$ With continuous illumination of RCs of WT $R$, sphaeroides, two solid-state mechanisms are active and run in parallel to induce net nuclear polarization that remains under steady-state conditions. ${ }^{26,27}$ (i) Electron-electronnuclear three-spin mixing (TSM) breaks the balance by coherent evolution of the correlated radical pair state in interaction with the nuclear spins and the applied magnetic field, depending on the signs of the electron-electron and of the anisotropic electron-nuclear interactions. ${ }^{38,39}$ (ii) In the electron-nuclear differential decay (DD) mechanism, ${ }^{40}$ only a single matching condition with a dependence of the secular part of the hyperfine coupling is required with the difference of singlet and triplet radical pair lifetimes on the order of the inverse hyperfine coupling. ${ }^{26}$ Understanding of the spinchemical processes ${ }^{28}$ allows one to apply photo-CIDNP MAS NMR as an analytical tool for elucidating electronic structures of the aromatic systems of the cofactors forming radical pairs. ${ }^{11}$ Here we apply photo-CIDNP MAS NMR to identify the signals of aliphatic side chain carbons in BChls that have been selectively isotope-labeled using $3{ }^{13} \mathrm{C}_{1}-\delta$-aminolevulinic acid (3-ALA), a precursor of the biosynthesis. This isotope label pattern is particularly desirable for detection of substituents (Figure 2). 


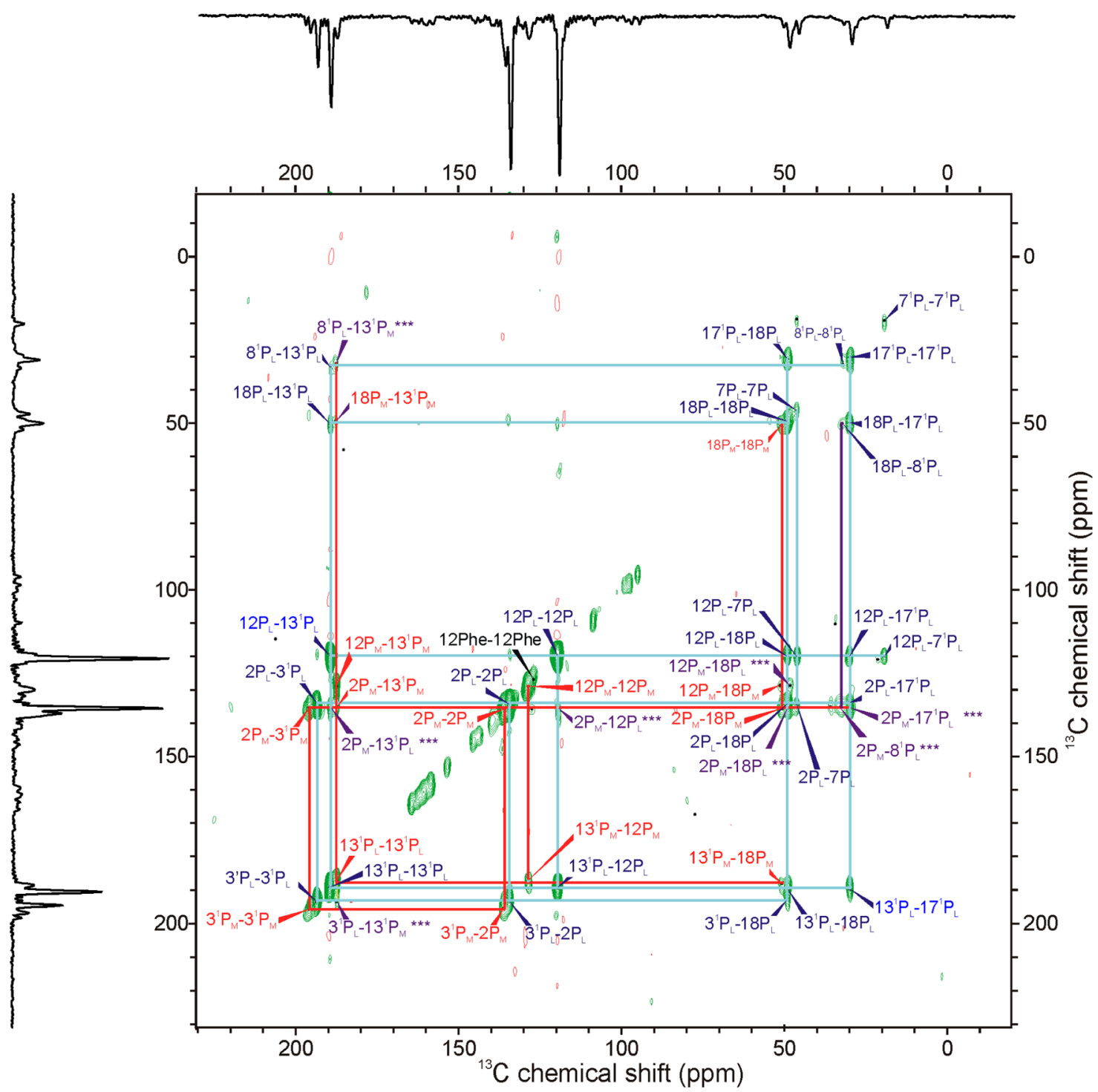

Figure 3. One-dimensional (at the top and the left side) and two-dimensional photo-CIDNP DARR MAS NMR spectra of 3-ALA-labeled RCs of WT R. sphaeroides obtained at a temperature of $223 \mathrm{~K}$ with a spin-diffusion mixing time of $2 \mathrm{~s}$ and a MAS frequency of $8 \mathrm{kHz}$. Two correlation networks are distinguished: one network is assigned to $P_{L}$ (blue), while the other is assigned to $P_{M}$ (red). Intermolecular cross-peaks are shown in purple.

\section{METHODS}

2.1. Sample Preparation. The selective isotope labeling in RCs of $R$. sphaeroides is achieved by feeding the bacteria with selectively labeled $3-{ }^{13} \mathrm{C}_{1}-\delta$-aminolevulinic acid (3-ALA), which is a precursor for the formation of $\mathrm{BChl} a$ and $\mathrm{BPhe}$, and leads to a ${ }^{13} \mathrm{C}$ enrichment of $\sim 60 \%$. The 3-ALA (Figure 2) has been purchased from Buchem B.V. (Apeldoorn, The Netherlands). The RCs were isolated as described earlier, ${ }^{41}$ and the quinones were removed by incubating the RCs at a concentration of $0.6 \mu \mathrm{M}$ in $4 \% \mathrm{LDAO}, 10 \mathrm{mM}$ o-phenanthroline, 10 $\mathrm{mM}$ Tris buffer, $\mathrm{pH} 8.0$, containing $0.025 \%$ LDAO and $1 \mathrm{mM}$ EDTA. $^{42}$ Approximately $15 \mathrm{mg}$ of RC protein complex embedded in LDAO micelles was used for the NMR experiment.

2.2. MAS NMR Experiments. NMR experiments were performed with a DMX-200 (4.7 T) NMR spectrometer equipped with a $4 \mathrm{~mm}$ MAS probe (Bruker BioSpin GmbH, Karlsruhe, Germany). The sample was loaded into a clear $4 \mathrm{~mm}$ sapphire rotor and inserted into the MAS probe. It was frozen slowly at a low spinning frequency of $600 \mathrm{~Hz}$ to ensure a homogeneous sample distribution against the rotor wall. $^{43}$

All two-dimensional (2D) ${ }^{13} \mathrm{C}-{ }^{13} \mathrm{C}$ photo-CIDNP DARR MAS NMR experiments were recorded with a MAS frequency of $8 \mathrm{kHz}$ and at a set temperature of $223 \mathrm{~K}$ using continuous illumination with white light. ${ }^{44}$ The spectra were measured in 64 scans with $200 t_{1}$ increments and a recycle delay of $4 \mathrm{~s}$, resulting in a total experiment time of $11 \mathrm{~h}$ for a mixing time of $2 \mathrm{~s}$. The FID was detected with proton decoupling using the TPPM sequence. ${ }^{45}$ The optimum length of the $(\pi / 2)$ carbon pulse, determined on uniformly ${ }^{13} \mathrm{C}$-labeled tyrosine, was $\sim 4.0 \mu \mathrm{s}$, corresponding with a nutation frequency of $62.5 \mathrm{kHz}$. All ${ }^{13} \mathrm{C}$ MAS NMR spectra were referenced to the carbonyl resonance of solid tyrosine $\cdot \mathrm{HCl}$ set to $172.1 \mathrm{ppm}$. Two-dimensional spectra were processed using the TopSpin (version 2.1) software package (Bruker BioSpin $\mathrm{GmbH}$, Rheinstetten, Germany). A sine-squared window function was applied along with zero filling to 1024 data points in both dimensions.

\section{RESULTS AND DISCUSSION}

3.1. Signal Assignment. Several ${ }^{13} \mathrm{C}$ resonances of the $\mathrm{BChl} a$ cofactors of the special pair have already been assigned in previous NMR studies on unlabeled ${ }^{15,46}$ and selectively with 4-ALA ${ }^{12,28}$ and 5-ALA ${ }^{47}$ labeled WT RCs. While the 4-ALA and 5-ALA label patterns allow the study of the aromatic carbons of the BChl and BPhe macrocycles, 3-ALA labeling 
leads to isotope enrichment of the more peripheral carbon positions (Figure 2). Such a pattern is particularly suitable for the observation of side chains.

Figure 3 presents both the one-dimensional (at the top and the left side) and the two-dimensional photo-CIDNP MAS NMR spectra of 3-ALA-labeled WT RC obtained by continuous illumination. The $1 \mathrm{D}$ spectrum demonstrates that all signals are emissive (negative). The negative sign of the signal has been explained by the dominance of the TSM over the DD mechanism. ${ }^{29}$ All 17 signals are light-induced, as shown by comparison to data collected in the dark (Supporting Information Figure S1). The line width of the aromatic signals is about $40 \mathrm{~Hz}$, as known from previous work. ${ }^{47,48}$ The signals appear to be very sharp, having almost equal line widths of 38 $\mathrm{Hz}$. The observation of very sharp lines from the cofactors seems to be a general feature of $\mathrm{RCs},{ }^{12,35,43}$ providing in the donor region a well-defined, well-ordered, and solid structure without protein disorder. It is remarkable also that the sidechain carbons show similarly sharp signals. The well-resolved signals at $C 17^{1}-\mathrm{P}_{\mathrm{L}}$ and $\mathrm{C} 7-\mathrm{P}_{\mathrm{L}}$, originating from side-chain carbons, have line widths of 38 and $39 \mathrm{~Hz}$, respectively. Hence, as the carbons of the aromatic rings, the side-chain carbons demonstrate the absence of static heterogeneity in the cofactor periphery and the protein pocket.

In the $2 \mathrm{D}$ experiment, the spin-diffusion mixing time was set to $2 \mathrm{~s}$ and was optimized to observe as many cross-peaks as possible. Since the radical pair $\left(\mathrm{P}_{\mathrm{L}} \mathrm{P}_{\mathrm{M}}\right)^{+} \Phi_{\mathrm{A}}{ }^{-}$is formed by three cofactors, the photo-CIDNP signals are from these three tetrapyrroles. ${ }^{28,47}$ In particular, there are two correlation networks originating from the BChl a cofactors (Figure 3). Earlier studies have demonstrated that $\mathrm{P}_{\mathrm{L}}$ carries a higher electron spin density and shows generally higher signal intensities than $\mathrm{P}_{\mathrm{M}}$, and in Figure 3, the network with the more intense signals is assigned to $\mathrm{P}_{\mathrm{L}}$ (labeled in blue) while the corresponding weaker network is assigned to $\mathrm{P}_{\mathrm{M}}$ (labeled in red).

Starting point for the assignments can be the $\mathrm{C} 3{ }^{1}$ resonances, which appear in the carboxylic region at lowest field (i.e., at $195.6 \mathrm{ppm}$ for the red and at $193.5 \mathrm{ppm}$ for the blue network). Alternatively, the signals of the two aromatic carbon positions, $\mathrm{C} 2$ and $\mathrm{C} 12$, provide a starting point since these carbons obtain the strongest enhancement by the solid-state photo-CIDNP effect. $^{29}$ In any case, the two networks can be completed straightforwardly. Since one C7/C8 cross-peak has already been assigned to the blue network, the second $\mathrm{C} 7 / \mathrm{C} 8$ cross-pair can be conveniently added into the red network. Both aliphatic carbons $\mathrm{C} 7$ and $\mathrm{C} 18$, located on the macrocycle, resonate with a chemical shift around $50 \mathrm{ppm}$. Two labeled side-chain carbons, $\mathrm{C}^{1}$ and $\mathrm{C} 17^{1}$, resonate around $30 \mathrm{ppm}$. Tables $\mathrm{S} 1$ and S2 summarize the assignments for $\mathrm{P}_{\mathrm{L}}$ and $\mathrm{P}_{\mathrm{M}}$, respectively. In addition, at $126.9 \mathrm{ppm}$ (C12 BPhe), a signal occurs without any correlation and is therefore assigned to the primary acceptor $\Phi_{\mathrm{A}}$.

The photo-CIDNP polarization transfer among the labeled ${ }^{13} \mathrm{C}$ atoms is mediated by spin diffusion, which operates through space and proceeds rapidly over short intra- and intermolecular distances. In addition, there are several intermolecular cross-peaks (labeled in purple) from correlations between $\mathrm{P}_{\mathrm{L}}$ and $\mathrm{P}_{\mathrm{M}}$. Examples of such correlations between $\mathrm{P}_{\mathrm{L}}$ and $\mathrm{P}_{\mathrm{M}}$ are $\mathrm{C}^{1}\left(\mathrm{P}_{\mathrm{L}}\right) / \mathrm{C} 13^{1}\left(\mathrm{P}_{\mathrm{M}}\right)(7.1 \AA), \mathrm{C}^{1}\left(\mathrm{P}_{\mathrm{L}}\right) / \mathrm{C}^{1} 3^{1}\left(\mathrm{P}_{\mathrm{M}}\right)$ $(7.1 \AA)$, and from $\mathrm{P}_{\mathrm{M}}$ to $\mathrm{P}_{\mathrm{L}}, \mathrm{C} 12\left(\mathrm{P}_{\mathrm{M}}\right) / \mathrm{C} 18\left(\mathrm{P}_{\mathrm{L}}\right)(13.1 \AA)$, $\mathrm{C} 2\left(\mathrm{P}_{\mathrm{M}}\right) / \mathrm{C} 18\left(\mathrm{P}_{\mathrm{L}}\right)(5.5 \AA), \mathrm{C} 2\left(\mathrm{P}_{\mathrm{M}}\right) / \mathrm{C}^{1}\left(\mathrm{P}_{\mathrm{L}}\right)(7.9 \AA), \mathrm{C} 2\left(\mathrm{P}_{\mathrm{M}}\right) /$ $\mathrm{C} 17^{1}\left(\mathrm{P}_{\mathrm{L}}\right)(6.3 \AA), \mathrm{C} 2\left(\mathrm{P}_{\mathrm{M}}\right) / \mathrm{C} 12\left(\mathrm{P}_{\mathrm{L}}\right)(8.4 \AA), \mathrm{C} 2\left(\mathrm{P}_{\mathrm{M}}\right) /$
$\mathrm{C} 13^{1}\left(\mathrm{P}_{\mathrm{L}}\right)\left(\begin{array}{ll}8.8 \AA & \AA\end{array}\right)$. These signals support the assignments obtained from the intramolecular networks.

3.2. Chemical Shift Pattern of the Special Pair. Based on the assignments described above for both $\mathrm{P}_{\mathrm{L}}$ and $\mathrm{P}_{\mathrm{M}}$, almost complete $\Delta \delta$ patterns of shifts relative to monomeric $\mathrm{BChl} a$ in acetone solution can be obtained (Figure 4 ). For both the $\mathrm{P}_{\mathrm{L}}$

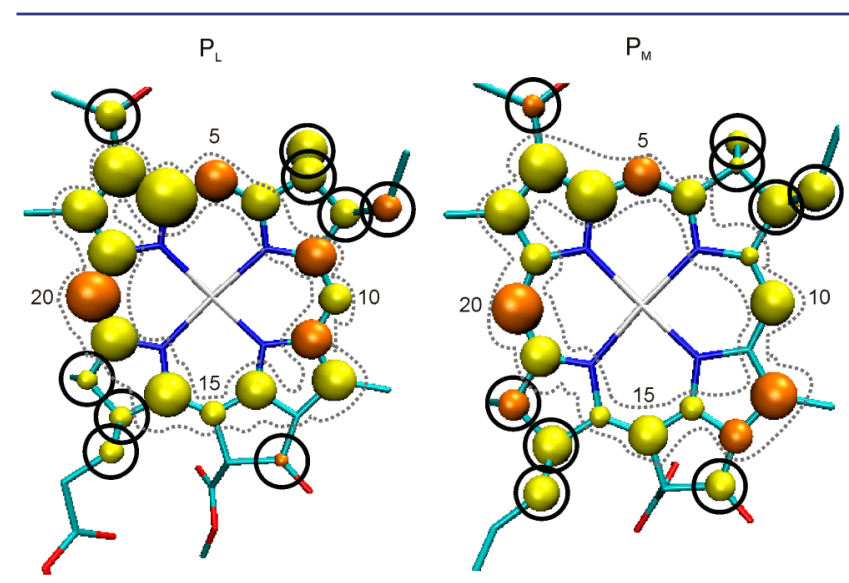

Figure 4. Cofactors $P_{L}$ (left) and $P_{M}$ (right) of the special pair. The spheres correspond with the difference in chemical shifts after the correction by the estimated ring current effects, which reflects the relative electron distribution for $\mathrm{P}_{\mathrm{L}}$ and $\mathrm{P}_{\mathrm{M}}$ in the electronic ground state derived experimentally. Yellow and orange spheres represent negative (shielding) and positive (deshielding) differences in chemical shifts $\Delta \delta$, respectively. The aromatic system of the macrocycle is indicated by an envelope of black dots. Identified substituent carbons are indicated by black circles. Obviously, the electron density is enriched in the overlap region as described before. ${ }^{11}$ The $\Delta \delta$ values appear to be slightly larger for the $\mathrm{P}_{\mathrm{L}}$ compared to the $\mathrm{P}_{\mathrm{M}}$. Comparing the signs of the $\Delta \delta$ for the aromatic carbons of $\mathrm{P}_{\mathrm{L}}$ vs $\mathrm{P}_{\mathrm{M}}$, not much difference can be observed. Except for carbons C9 and C12, the sign patterns are the same for both macrocyclic aromatic systems. This is remarkable and reflects a similar $\pi$-orbital architecture in both cofactors. On the other hand, comparing the signs of the $\Delta \delta$ for the peripheral carbons of $\mathrm{P}_{\mathrm{L}}$ and $\mathrm{P}_{\mathrm{M}}$, we find a significantly inverted pattern. Carbons $\mathrm{C} 3^{1}, \mathrm{C} 8^{1}, \mathrm{C} 13^{1}$, and $\mathrm{C} 18$ have opposite signs between the two special pair cofactors. In addition, the other five peripherial carbons $\mathrm{C} 7, \mathrm{C} 7{ }^{1}, \mathrm{C} 8, \mathrm{C} 17$, and $\mathrm{C} 17^{1}$ show significant variations of the $\Delta \delta$ between the $\mathrm{P}_{\mathrm{L}}$ and $\mathrm{P}_{\mathrm{M}}$.

and $\mathrm{P}_{\mathrm{M}}$, the $\Delta \delta$ values have been corrected for ring current shifts from the adjacent $\mathrm{BChl} .{ }^{11}$ Hence, negative sign $\Delta \delta<0$ indicates that the corresponding ${ }^{13} \mathrm{C}$ nucleus is more shielded (indicated in yellow), while a positive $\Delta \delta$ indicates deshielding (indicated in orange) relative to the signal of the same carbon of a $\mathrm{BChl}$ a cofactor in acetone solution. This implies that yellow-labeled carbons are enriched in ground-state electron density compared to monomeric BChl $a$ in solution.

3.3. Role of Side Chains. Recent modeling studies by Yamasaki et al. proposed a crucial role of the side-chain geometry for the functional symmetry break of the special pair. ${ }^{25}$ For example, in that work, it has been shown that conformational changes on the methyl ester and phytyl side chains can shift the ratio of electron spin densities in the radical cation state between $P_{L}$ and $P_{M}$ from almost 100:0 to 0:100. While chemical shifts of aromatic carbons are generally thought to reflect atomic charge densities in the $\pi$-system, for aliphatic carbons, the shift differences between the two halves reflect conformational differences. Hence, the photo-CIDNP data provide an experimental underpinning of the inferences from the modeling studies and demonstrate that the tuning of the 
aromatic systems by the side chains is indeed significantly different for the two halves of P. While the side-chain carbons of $\mathrm{P}_{\mathrm{L}}$ show mainly upfield shifts, for the side-chain carbons of the $\mathrm{P}_{\mathrm{M}}$ cofactors, mainly downfield shifts are observed. This implies contrasting conformational control by protein on the side chains of $\mathrm{P}_{\mathrm{L}}$ and $\mathrm{P}_{\mathrm{M}}$. The side chains of $\mathrm{P}_{\mathrm{L}}$ have an electron-donating character, while the side chains of $\mathrm{P}_{M}$ withdraw electron density from the aromatic macrocycle. The relevance of side-chain pocket interactions is underlined by the high order observed in the entire pocket, ${ }^{11,12,43,48}$ including the side chains of the cofactors. Such systematic control by the matrix allows the side chains to play a defined role in tuning the electronic properties of the two aromatic macrocycles.

\section{CONCLUSIONS}

The special pair, as indicated by the majority of upfield shifts (Figure 4), carries excess of negative charge, ${ }^{11}$ which is caused by charge donation of the axial histidines. ${ }^{49}$ In the dark ground state, the excess charge is mainly localized on ring $\mathrm{P}_{\mathrm{L}}$ in the overlapping region toward ring $\mathrm{P}_{\mathrm{M}} \cdot{ }^{11,29}$ That observation is inline with electron spin density distribution in the radical cation state, being in favor of $\mathrm{P}_{\mathrm{L}}$ and reflecting the properties of the HOMO. ${ }^{10,11,25,29}$ On the other hand, in the excited state, electron charge is mainly localized on $\mathrm{P}_{\mathrm{M}},{ }^{30,50,51}$ from where it is transferred into the nearby active branch. As shown here, the aliphatic periphery can stabilize the charge distribution in the excited state by pushing electron density into $\mathrm{P}_{\mathrm{L}}{ }^{+}$and pulling electron density from $\mathrm{P}_{\mathrm{M}}{ }^{-}$.

Our data support the idea that the symmetry break is due to internal factors, in particular, due to the conformation of the special pair. Recently, we have shown that the bacteriopheopytin acceptor is not particularly tuned and cannot provide an explanation for the functional symmetry break. ${ }^{52}$ In this picture, also the role of the protein environment is limited to stabilize that conformation. It has been proposed by Shelnut that conformations of tetrapyrrole macrocycles are related to function and conserved in evolution. ${ }^{53}$ This concept has been applied to photosynthetic electron donors. ${ }^{35}$ Our data suggest also that side-chain conformations have to be included with this concept.

\section{ASSOCIATED CONTENT}

\section{S Supporting Information}

One-dimensional photo-CIDNP DARR MAS NMR spectra of 3-ALA-labeled RCs of WT R. sphaeroides and NMR chemical shifts of $\mathrm{P}_{\mathrm{L}}$ and $\mathrm{P}_{\mathrm{M}}$ are displayed. This material is available free of charge via the Internet at http://pubs.acs.org.

\section{AUTHOR INFORMATION}

\section{Corresponding Author}

joerg.matysik@uni-leipzig.de

\section{Notes}

The authors declare no competing financial interest.

\section{ACKNOWLEDGMENTS}

This work has been supported by funds from NWO for generous support (ALW open competitie, 818.02.019; Middelgroot 700.57.107). Part of this work is financially supported by the Cyttron program in advanced integrated bioimaging technologies. Support from F. Lefeber and K. Erkelens during various stages of the experiments is gratefully acknowledged.

\section{REFERENCES}

(1) Kippelen, B.; Brédas, J. L. Proc. Soc. Photo-Opt. Instrum. Eng. 2009, 2, 251-261.

(2) Noy, D.; Moser, C. C.; Dutton, P. L. Biochim. Biophys. Acta 2006, $1757,90-105$.

(3) Camara-Artigas, A.; Brune, D.; Allen, J. P. Proc. Natl. Acad. Sci. U.S.A. 2002, 99, 11055-11060.

(4) Ermler, U.; Fritzsch, G.; Buchanan, S. K.; Michel, H. Structure 1994, 2, 925-936.

(5) Hoff, A. J.; Deisenhofer, J. Phys. Rep. 1997, 287, 2-247.

(6) The Purple Phototrophic Bacteria; Hunter, C. N., Daldal, F., Thurnauer, M. C., Beatty, J. T., Eds.; Springer: Dordrecht, The Netherlands, 2008; Vol. 28.

(7) Santabarbara, S.; Kuprov, I.; Fairclough, W.; Purton, S.; Hore, P.; Heathcote, P.; Evans, M. Biochemistry 2005, 44, 2119-2128.

(8) Poluektov, O.; Paschenko, S.; Utschig, L.; Lakshmi, K.; Thurnauer, M. J. Am. Chem. Soc. 2005, 127, 11910-11911.

(9) Feher, G.; Allen, J. P.; Okamura, M. Y.; Rees, D. C. Nature 1989, 339, 111-116.

(10) Lendzian, F.; Huber, M.; Isaacson, R. A.; Endeward, B.; Plato, M.; Bönigk, B.; Mobius, K.; Lubitz, W.; Feher, G. Biochim. Biophys. Acta 1993, 1183, 139-160.

(11) Daviso, E.; Prakash, S.; Alia, A.; Gast, P.; Neugebauer, J.; Jeschke, G.; Matysik, J. Proc. Natl. Acad. Sci. U.S.A. 2009, 106, 2228122286.

(12) Schulten, E. A. M.; Matysik, J.; Alia; Kiihne, S.; Raap, J.; Lugtenburg, J.; Gast, P.; Hoff, A. J.; de Groot, H. J. M. Biochemistry 2002, 41, 8708-8717.

(13) Palaniappan, V.; Bocian, D. F. J. Am. Chem. Soc. 1995, 117, 3647-3648.

(14) Lubitz, W.; Feher, G. Appl. Magn. Reson. 1999, 17, 1-48.

(15) Prakash, S.; Alia; Gast, P.; de Groot, H. J. M.; Matysik, J.; Jeschke, G. J. Am. Chem. Soc. 2006, 128, 12794-12799.

(16) Marchanka, A.; Lubitz, W.; van Gastel, M. J. Phys. Chem. B 2009, 113, 6917-6927.

(17) Vos, M. H.; Lambry, J. C.; Robles, S. J.; Youvan, D. C.; Breton, J.; Martin, J. L. Proc. Natl. Acad. Sci. U.S.A. 1991, 88, 8885-8889.

(18) Vos, M. H.; Rappaport, F.; Lambry, J. C.; Breton, J.; Martin, J. L. Nature 1993, 363, 320-325.

(19) Vos, M. H.; Jones, M. R.; Hunter, C. N.; Breton, J.; Martin, J. L. Proc. Natl. Acad. Sci. U.S.A. 1994, 91, 12701-12705.

(20) Vos, M. H.; Rischel, C.; Jones, M. R.; Martin, J.-L. Biochemistry 2000, 39, 8353-8361.

(21) Reddy, N. R. S.; Kolaczkowski, S. V.; Small, G. J. Science 1993, 260, 68-71.

(22) Reddy, N. R. S.; Kolaczkowski, S. V.; Small, G. J. J. Phys. Chem. 1993, 97, 6934-6940.

(23) Novoderezhkin, V. I.; Yakovlev, A. G.; van Grondelle, R.; Shuvalov, V. A. J. Phys. Chem. B 2004, 108, 7445-7457.

(24) Eisenmayer, T. J.; de Groot, H. J. M.; van de Wetering, E.; Neugebauer, J.; Buda, F. J. Phys. Chem. Lett. 2012, 3, 694-697.

(25) Yamasaki, H.; Takano, Y.; Nakamura, H. J. Phys. Chem. B 2008, $112,13923-13933$.

(26) Jeschke, G.; Matysik, J. Chem. Phys. 2003, 294, 239-255.

(27) Daviso, E.; Jeschke, G.; Matysik, J. In Biophysical Techniques in Photosynthesis II; Aartsma, T., Matysik, J., Eds.; Springer: Dordrecht, The Netherlands, 2008; pp 385-399.

(28) Daviso, E.; Alia, A.; Prakash, S.; Diller, A.; Gast, P.; Lugtenburg, J.; Matysik, J.; Jeschke, G. J. Phys. Chem. C 2009, 113, 10269-10278.

(29) Prakash, S.; Alia; Gast, P.; de Groot, H. J. M.; Jeschke, G.; Matysik, J. J. Am. Chem. Soc. 2005, 127, 14290-14298.

(30) Thamarath, S. S.; Bode, B. E.; Prakash, S.; Sai Sankar Gupta, K. B.; Alia, A.; Jeschke, G.; Matysik, J. J. Am. Chem. Soc. 2012, 134, 59215930.

(31) Roy, E.; Rohmer, T.; Gast, P.; Jeschke, G.; Alia, A.; Matysik, J. Biochemistry 2008, 47, 4629-4635.

(32) Roy, E.; Alia, A.; Gast, P.; de Groot, H.; Jeschke, G.; van Gorkom, H.; Matysik, J. Photosynth. Res. 2007, 91, PS248. 
(33) Matysik, J.; Alia; Gast, P.; van Gorkom, H. J.; Hoff, A. J.; de Groot, H. J. M. Proc. Natl. Acad. Sci. U.S.A. 2000, 97, 9865-9870.

(34) Alia, A.; Roy, E.; Gast, P.; van Gorkom, H. J.; de Groot, H. J. M.; Jeschke, G.; Matysik, J. J. Am. Chem. Soc. 2004, 126, 12819-12826.

(35) Diller, A.; Roy, E.; Gast, P.; van Gorkom, H. J.; de Groot, H. J. M.; Glaubitz, C.; Jeschke, G.; Matysik, J.; Alia, A. Proc. Natl. Acad. Sci. U.S.A. 2007, 104, 12767-12771.

(36) Janssen, G. J.; Daviso, E.; van Son, M.; de Groot, H. J. M.; Alia, A.; Matysik, J. Photosynth. Res. 2010, 104, 275-282.

(37) Thamarath, S. S.; Alia, A.; Daviso, E.; Mance, D.; Golbeck, J. H.; Matysik, J. Biochemistry 2012, 51, 5763-5773.

(38) Jeschke, G. J. Chem. Phys. 1997, 106, 10072-10086.

(39) Jeschke, G. J. Am. Chem. Soc. 1998, 120, 4425-4429.

(40) Polenova, T.; McDermott, A. E. J. Phys. Chem. B 1999, 103, $535-548$.

(41) Shochat, S.; Arlt, T.; Francke, C.; Gast, P.; Vannoort, P. I.; Otte, S. C. M.; Schelvis, H. P. M.; Schmidt, S.; Vijgenboom, E.; Vrieze, J.; Zinth, W.; Hoff, A. J. Photosynth. Res. 1994, 40, 55-66.

(42) Okamura, M. Y.; Isaacson, R. A.; Feher, G. Proc. Natl. Acad. Sci. U.S.A. 1975, 72, 3491-3495.

(43) Fischer, M. R.; de Groot, H. J. M.; Raap, J.; Winkel, C.; Hoff, A. J.; Lugtenburg, J. Biochemistry 1992, 31, 11038-11049.

(44) Matysik, J.; Alia; Hollander, J.; Egorova-Zachernyuk, T.; Gast, P.; de Groot, H. J. M. Indian J. Biochem. Biophys. 2000, 37, 418-423.

(45) Bennett, A. E.; Rienstra, C. M.; Auger, M.; Lakshmi, K. V.; Griffin, R. G. J. Chem. Phys. 1995, 103, 6951-6958.

(46) Daviso, E.; Prakash, S.; Alia, A.; Gast, P.; Jeschke, G.; Matysik, J. Appl. Magn. Reson. 2009, 37, 49-63.

(47) Prakash, S.; Alia, A.; Gast, P.; de Groot, H. J. M.; Jeschke, G.; Matysik, J. Biochemistry 2007, 46, 8953-8960.

(48) Matysik, J.; Schulten, E.; Alia; Gast, P.; Raap, J.; Lugtenburg, J.; Hoff, A. J.; de Groot, H. J. M. Biol. Chem. 2001, 382, 1271-1276.

(49) Alia, A.; Wawrzyniak, P. K.; Janssen, G. J.; Buda, F.; Matysik, J.; de Groot, H. J. M. J. Am. Chem. Soc. 2009, 131, 9626-9627.

(50) Lockhart, D. J.; Boxer, S. G. Biochemistry 1987, 26, 664-668.

(51) Lockhart, D. J.; Boxer, S. G. Proc. Natl. Acad. Sci. U.S.A. 1988, $85,107-111$.

(52) Sai Sankar Gupta, K. B.; Alia, A.; Buda, F.; de Groot, H. J. M.; Matysik, J. J. Phys. Chem. B 2013, 117, 3287-97.

(53) Shelnutt, J. A.; Song, X. Z.; Ma, J. G.; Jia, S. L.; Jentzen, W.; Medforth, C. J. Chem. Soc. Rev. 1998, 27, 31-41. 